\title{
Mechanical Characteristics of Aluminium Powder Filled Glass Epoxy Composites
}

\author{
Pujan Sarkar ${ }^{1}$, Nipu Modak ${ }^{1}$, Prasanta Sahoo $^{1^{*}}$ \\ ${ }^{1}$ Department of Mechanical Engineering, Jadavpur University, Kolkata 700032, India \\ *Corresponding author (E-mail: psjume@gmail.com)
}

\begin{abstract}
Keywords: Aluminium Powder, Glass Fiber, Epoxy, Tensile strength, Tensile modulus, Flexural strength, Inter laminar shear strength
\end{abstract}

\begin{abstract}
Mechanical characteristics of glass epoxy and aluminium powder filled glass epoxy composites are experimentally investigated using INSTRON 8801 testing device as per ASTM standards. With a fixed $w t \%$ of fiber reinforcement, glass epoxy and 5-15 wt $\%$ aluminium powder filled glass epoxy composites are fabricated in conventional hand lay-up technique followed by light compression moulding process. Experimental results show that aluminium powder as a filler material influences the mechanical properties. Density and void fraction in composites increase whereas steady decrease of tensile strength is recorded with aluminium powder addition. Micro hardness, flexural strength, inter laminar shear strength (ILSS) of 5 and $10 \mathrm{wt} \%$ aluminium content composites are improved compared to unfilled glass epoxy composite and with further addition of aluminium up to $15 \mathrm{wt} \%$ decreasing trends are observed. Glass epoxy with $5 \mathrm{wt} \%$ aluminium concentration shows the highest improvement. Tensile modulus for aluminium addition of $5 \mathrm{wt} \%$ decreases whereas $10 \mathrm{wt} \%$ aluminium filled composite shows improvement in tensile modulus. These are explained on the basis of material properties, void fractions and bonding strength among the constituents.
\end{abstract}

\section{Introduction}

Glass fiber reinforced epoxy composites are very popular in composite industry for its increasing use in numerous engineering applications such as seals, gears, rollers, cams, wheel, clutches and bearings because of many advantages including improved mechanical properties, wide varieties of availability and design flexibility as compared to metal based counterparts. As a reinforcing material, glass fiber has a wide range of availability [1] out of which bi-directional woven glass fiber reinforced polymer composites are getting acceptance in many industrial applications due to low weight, ease of processing and price. It provides better resistance to impact than unidirectional composites and display behavior that is closer to a fully isotropic material [2-3]. The mechanical performance of glass epoxy composite can be further improved by incorporation of filler particles. The reason to incorporate filler in glass epoxy is to enhance specific properties and to reduce the cost of the final product. Glass fiber reinforced epoxy composites containing different filler are used in many applications where mechanical properties are the critical issues [4-10]. Most of the studies made on particulate filled glass fiber reinforced epoxy composites reveal that the mechanical properties are strongly influenced by many factors such as type of filler and glass fibers, their volume/weight fraction, aspect ratio, strength and modulus; fiber orientation, type of matrix, matrix strength and the interface bonding among the filler/fiber and matrix to enable stress transfer at the interface etc [11]. Among the factors, filler material and proportion in composite are very significant in respect to the mechanical properties. Many investigations are reported with the use of ceramic, natural and other types of particles as filler material but when weight reduction is one of the major issues for composites, the use of soft particles is required to be explored much. Suresha et al. [12] studied the mechanical properties of glass-fiber-reinforced epoxy composites with and without graphite particulate filler. Experimental investigation reveals that tensile strength and dimensional stability of the glass epoxy composite increased with increasing graphite content. The effect of $\mathrm{CaCO}_{3}$ as a filler in E-glass/ epoxy composites on mechanical properties has been studied 
by Paliwal and Chaturvedi [13]. Yusriah et al. [14] studied the effect of particulate fillers on specific mechanical properties of vinyl ester epoxy reinforced with woven glass fiber composites with different filler of calcium carbonate and phenolic hollow microspheres and particulate filler contents $(1 \%, 3 \%$, and $5 \%$ by wt). Woven glass fabric composites filled with particulate phenolic hollow microspheres were observed to have better specific flexural strength and specific impact strength, as well as lower density as compared to those filled with particulate calcium carbonate. The use of other particles like mica in glass epoxy composite is helpful to improve the hardness and compressive strength of unidirectional E-glass fiber reinforced epoxy composite [15]. Similarly, the soft particles i.e particles of mica and tricalcium phosphate in glass epoxy composite improved the mechanical properties based on the filler contributing to the bonding strength between fiber and epoxy resin [16]. Hybrid composites consisting of bi-directional E-glass-fiber reinforced epoxy filled with different Linz-donawitz (LD) slag content $(0,7.5,15,22.5 \mathrm{wt} \%)$ were studied by Pati and Satapathy [17] who opined that LD slag, in spite of being a waste, possesses fairly good filler characteristics as it modifies the strength properties and improves the composite micro-hardness.

Aluminium possesses low weight, high strength, superior malleability, easy machining, and excellent corrosion resistance, good thermal and electrical conductivity. Aluminium is also very easy to recycle [18]. Mechanical properties including hardness, dimension accuracy and thermal conductivity is improved by incorporation of aluminium powder with epoxy resin [19-22]. It is also established that on decreasing the particle size, mechanical properties improve more whereas with the increase of particle size, improvement of thermal conductivity is more. Hence selection of particle size of aluminium powder requires more attention. Extensive literature survey reveals that very few researchers have attempted to explore the mechanical behavior of aluminium filled glass epoxy composites considering different process parameters. In tri-phase materials, composed of an epoxy resin, aluminium particles and milled fibers, Vasconcelos et al. [23] observed that the mechanical and thermal performances are better than the single materials. This was established through a Charpy impact tests with electronic instrumentation. Hamed [24] investigated the tensile strength of aluminium powder mixed glass/ kevlar/ PVC fiber reinforced epoxy composites. He showed that the tensile strength increased with increased volume fraction of aluminium powder from $20 \%$ to $40 \%$ and the sample kevlar epoxy had higher tensile strength than all other samples for both volume fractions.

In general, researchers have attempted to evaluate the thermal properties of such composites and the role of aluminium incorporation in polymer composites. Though there may be many benefits of using aluminium filler in polymer composites, but the use of this material for the improvement of mechanical properties is yet to be reported. The present work is an attempt to fill this void. In the present research work, the effects of addition of aluminium powder on mechanical properties of woven glass epoxy composites have been studied. This work would be a great help in understanding the function of aluminium powder in glass epoxy composite.

\section{Experimental Work}

Materials. Medium viscosity epoxy resin (ARALDITE CY 205 IN) with glass transition temperature (Tg) of $108^{0} \mathrm{C}$ and curing agent hardener (HY 951) at room temperature constitute the matrix system. Fine aluminium powder, average particle size not exceeding 40 micron with a purity of about $98.70 \%$ is used as filler material. As reinforcement, woven roving glass fiber containing E-glass fibers of diameter 5-10 $\mu \mathrm{m}$, orientation $0 / 90^{\circ}$, density $2.59 \mathrm{gm} / \mathrm{cm}^{3}$ and $360 \mathrm{gsm}$, has been used. Fig. 1 (a) and 1(b) represent the aluminium powder and SEM photograph of aluminium particles respectively. Fig. 1(c) shows the woven E glass fabric and Fig. 1(d) represents the geometry of fiber orientation. 


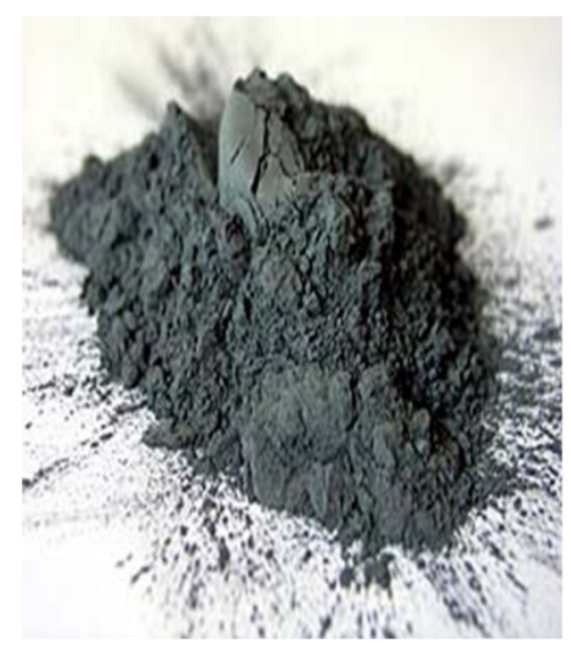

(a)

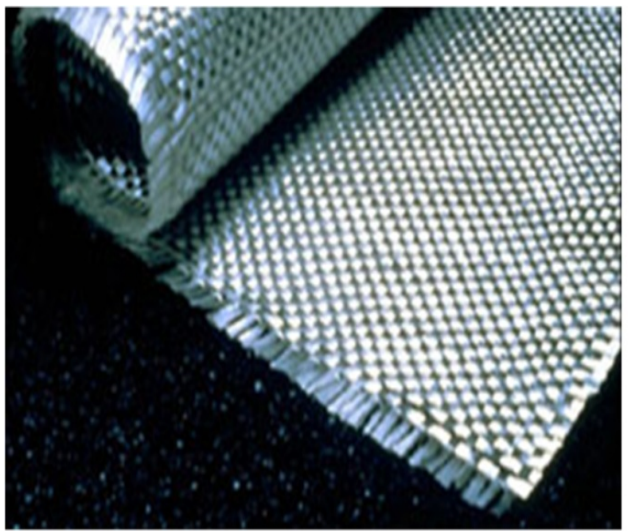

(c)

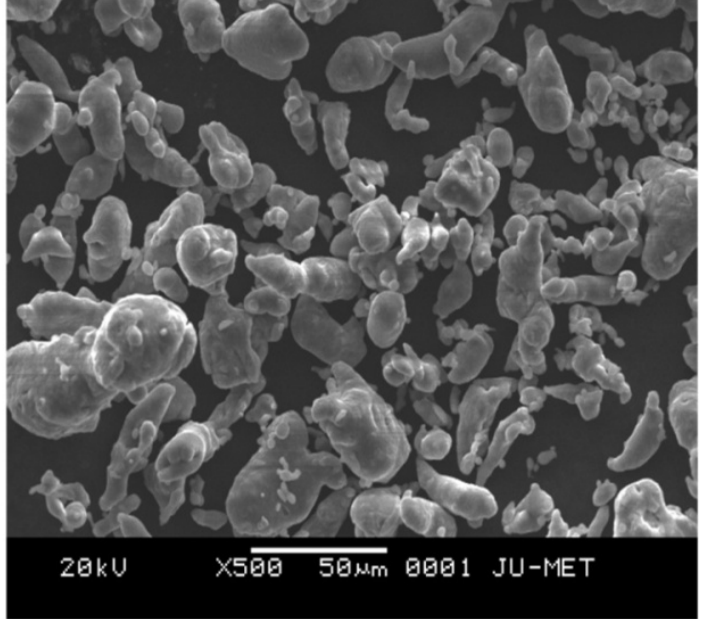

(b)

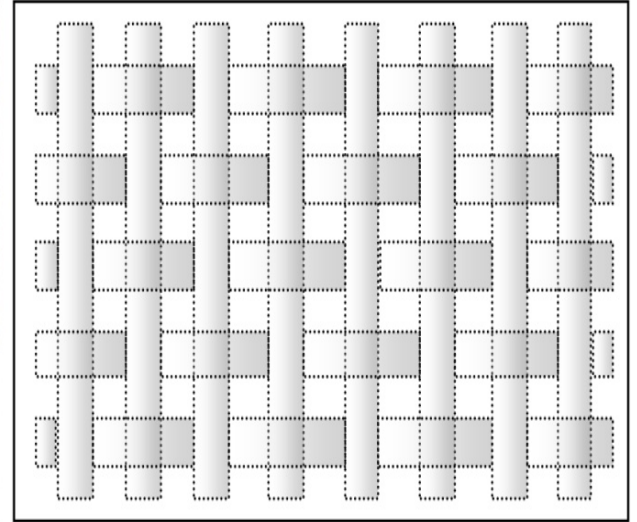

(d)

Figure 1. a) Aluminium powder; b) SEM photograph of aluminium particles, c) Woven E glass fabric; d) geometry of fiber orientation.

Some details of the constituent matrix materials and mechanical properties of epoxy resin, glass fiber and aluminium powder are shown in Table 1 and Table 2 respectively. At a glance, the mechanical properties of aluminium do not suggest its use as a filler material for improvement in mechanical properties. However, researchers have incorporated aluminium into such composites particularly to improve the thermal properties of such composites. From that perspective, here an attempt is made to see even if one needs to incorporate aluminium for improvement of thermal properties then up to what extent so that there is not much degradation in mechanical properties.

Table 1. Properties of epoxy resin and hardener.

\begin{tabular}{|c|c|c|c|c|}
\hline Material & $\begin{array}{c}\text { Trade and } \\
\text { chemical name }\end{array}$ & $\begin{array}{c}\text { Epoxide } \\
\text { equivalent }\end{array}$ & $\begin{array}{c}\text { Density } \\
\left(\mathrm{gm} / \mathrm{cm}^{3}\right)\end{array}$ & $\begin{array}{c}\text { Parts by } \\
\text { weight }\end{array}$ \\
\hline Resin & Araldite CY 205 IN & $182-196$ & 1.27 & 100 \\
\hline Hardener & Hardener, HY 951 & ------ & 0.94 & 10 \\
\hline
\end{tabular}

Table 2. Mechanical properties of epoxy, glass fiber, and aluminium powder.

\begin{tabular}{|c|c|c|c|}
\hline Property & Epoxy & Glass & Aluminium powder \\
\hline Tensile strength GPa & 0.11 & 3.4 & $47 \times 10^{-3}$ \\
\hline Elastic modulas GPa & 4.1 & 72.3 & 70 \\
\hline Poision's ratio & 0.35 & 0.2 & 0.33 \\
\hline
\end{tabular}


Fabrication of Composites. The designation and composition of the composites prepared for this study are listed in Table 3. The composite $\mathrm{C}$ with fixed amount of fiber reinforcement $(60 \mathrm{wt} \%)$ and $0 \mathrm{wt} \%$ of aluminium content is termed as unfilled glass epoxy or simply glass epoxy composite. In composites $D_{1}-D_{3}$, the quantity of glass fiber has been maintained fixed at $60 \mathrm{wt} \%$. Aluminium wt $\%$ varies as $0,5,10$, and 15 for each composite. The fabrication of the composite slabs $\mathrm{C}$ and $\mathrm{D}$ are done by conventional hand-lay-up technique followed by light compression moulding. All the composites ( $\mathrm{C}$ and $\mathrm{D})$ are fabricated in three steps. On the basis of the mould dimension, certain pre calculation is exercised to determine each constituent quantity. It is essential to maintain the desired $\mathrm{wt} \%$ of constituents in composites.

Table 3. Designations and compositions of the fabricated composites.

\begin{tabular}{|c|c|c|}
\hline Sample code & Designation & Composition \\
\hline C & GE & Epoxy $(40 w t \%)+$ Glass Fiber $(60 w t \%)$ \\
\hline $\mathrm{D}_{1}$ & 5AlGE & $\begin{array}{c}\text { Epoxy }\left(35 w^{2} \%\right)+\text { Glass Fiber }(60 w t \%) \\
+ \text { Aluminium }(5 \mathrm{wt} \%)\end{array}$ \\
\hline $\mathrm{D}_{2}$ & 10AlGE & $\begin{array}{c}\text { Epoxy }\left(30 \mathrm{wt}^{0} \%\right)+\text { Glass Fiber }(60 \mathrm{wt} \%) \\
+ \text { Aluminium }(10 \mathrm{wt} \%)\end{array}$ \\
\hline $\mathrm{D}_{3}$ & $15 \mathrm{AlGE}$ & $\begin{array}{c}\text { Epoxy }(25 \mathrm{wt} \%)+\text { Glass Fiber }(60 \mathrm{wt} \%) \\
+ \text { Aluminium }(15 \mathrm{wt} \%)\end{array}$ \\
\hline
\end{tabular}

Required numbers of woven fabric of $150 \mathrm{~mm} \times 100 \mathrm{~mm}$ size is cut with the help of a steel rule and sharp cutter on a wooden platform without disturbing the actual fiber orientation. For unfilled glass epoxy composite, a dry and clean glass container with a starrer is put on a weighting machine and reading is set to zero. Epoxy resin, Araldite CY-205 IN is slowly poured in the glass container till the machine display the required reading. Hardener (HY 951) at a ratio 10:1 by weight of resin is added to the epoxy and stirred mechanically for about ten minutes for proper mixing and exothermic reaction is just about to start. In case of aluminium particulate composites, aluminium powder is added to the epoxy resin first and mixed well in continuous stirring process then the hardener is added with the aluminium epoxy mixture. Stirring of the mixture continues for a certain duration based on the exothermic reaction. A specially designed and fabricated HSS mould (Fig. 2) is used for this purpose to avoid bending during compression. The inner sides of the mould is covered with very thin tear resistant plastic film of few microns thickness to perform the similar function of releasing agent to avoid the possibility of infusion of releasing agent into the glass fiber. Epoxy (resin and hardener) or aluminium mixed epoxy is lapped on the woven fibers uniformly and then the wetted fibers are placed one above the other into the mould. The whole assembly is pressed in a hydraulic press $(20 \mathrm{~kg}$ ) and is left for 24 (twenty four) hours at room temperature. The compression ensures that the entrapped air bubbles are completely removed with the excess resin. After demoulding, post curing is done at room temperature for 48 hour to complete the fabrication process.
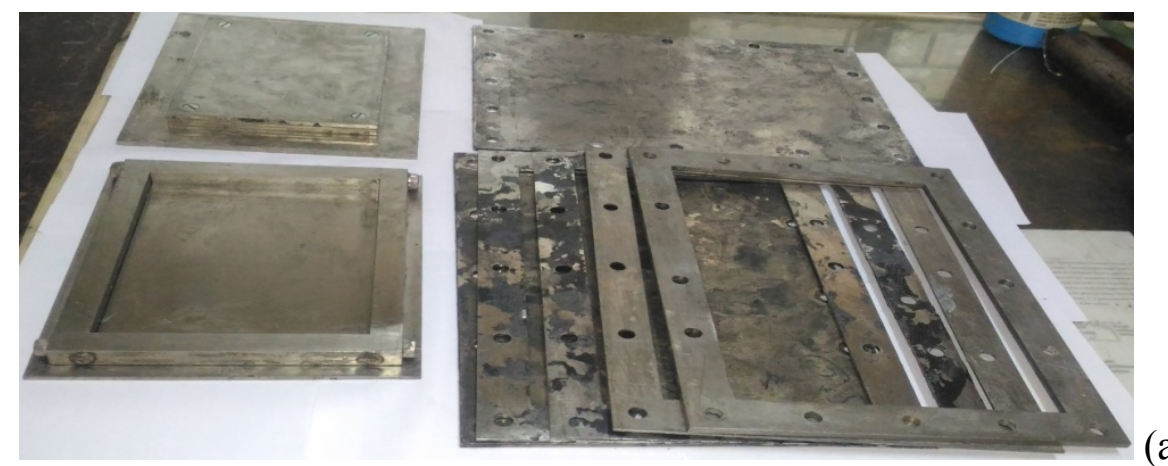


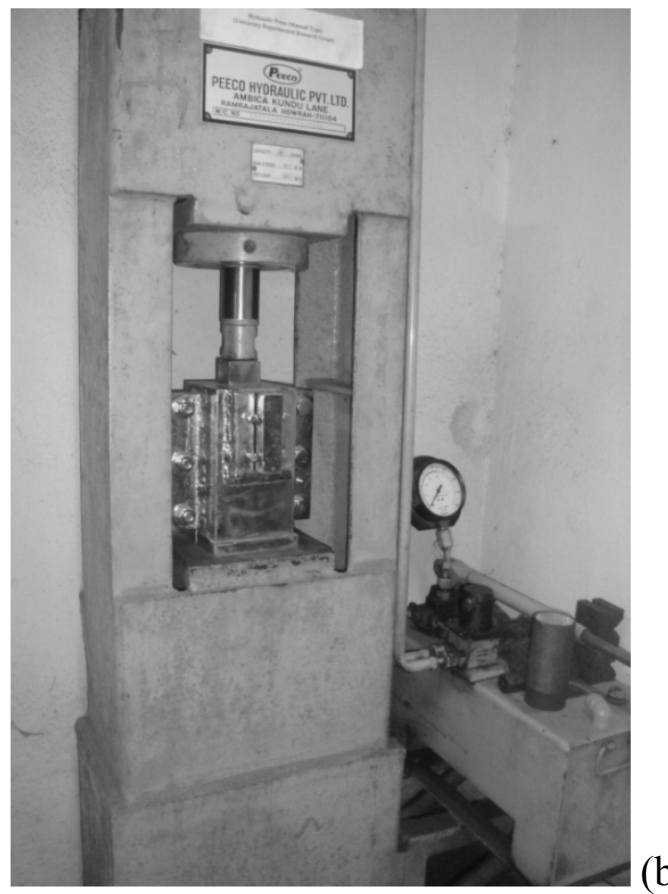

Figure 2. (a) Mould and (b) hydraulic press used for composite fabrication.

Table 4. Dimensions of different test samples.

\begin{tabular}{|c|c|c|}
\hline Serial no & Name of the test & Sample dimension \\
\hline 1 & Density & $30 \mathrm{~mm} \times 12 \mathrm{~mm} \times 6 \mathrm{~mm}$ \\
\hline 2 & Micro hardness & $16 \mathrm{~mm} \times 12 \mathrm{~mm} \times 6 \mathrm{~mm}$ \\
\hline 3 & Tensile strength (ASTM D3039-07) & $150 \mathrm{~mm} \times 12 \mathrm{~mm} \times 6 \mathrm{~mm}$ \\
\hline 4 & Flexural test (ASTM D790-10) & $60 \mathrm{~mm} \times 12 \mathrm{~mm} \times 6 \mathrm{~mm}$ \\
\hline 5 & Inter laminar shear strength (ILSS) & $60 \mathrm{~mm} \times 12 \mathrm{~mm} \times 6 \mathrm{~mm}$ \\
\hline
\end{tabular}

Specimens of required dimensions for mechanical characterization are cut by a diamond cutter. Fine cutting of the samples are carried out with the help of perma grit hacksaw, flat file, sanding block. Final finishing of the surfaces is done with 600 grade and 1000 grade SiC paper. Dimensions of the different samples used for mechanical characterization are shown in Table 4.

\section{Test Procedure}

Density. The theoretical density $\left(\rho_{\mathrm{ct}}\right)$ of composite materials in terms of weight fractions of different constituents can easily be obtained using the following equation [25].

$$
\rho_{\mathrm{ct}}=\frac{1}{\left(\frac{\mathrm{w}_{\mathrm{f}}}{\rho_{\mathrm{f}}}\right)+\left(\frac{\mathrm{w}_{\mathrm{m}}}{\rho_{\mathrm{m}}}\right)},
$$

where $\mathrm{W}$ and $\rho$ represent the weight fraction and density respectively. The suffixes $\mathrm{f}$ and $\mathrm{m}$ stand for the fiber and matrix respectively. Since the composites under this investigation consist of three components namely matrix, fiber and particulate filler, the expression for the density is modified as

$$
\rho_{\mathrm{ct}}=\frac{1}{\left(\frac{\mathrm{w}_{\mathrm{f}}}{\rho_{\mathrm{f}}}\right)+\left(\frac{\mathrm{w}_{\mathrm{m}}}{\rho_{\mathrm{m}}}\right)+\left(\frac{\mathrm{w}_{\mathrm{p}}}{\rho_{\mathrm{p}}}\right)},
$$

where the suffix $p$ stands for the particulate filler. The actual density $\left(\rho_{\mathrm{ca}}\right)$ of the composite is however, determined experimentally by simple water immersion technique with the use of the sample of $30 \mathrm{~mm} \times 12 \mathrm{~mm} \times 6 \mathrm{~mm}$ dimensions. Four samples of same composite are tested and average value is presented. The volume fraction of voids $\left(\mathrm{V}_{\mathrm{v}}\right)$ in the composites is calculated using the following equation: 


$$
\mathrm{V}_{\mathrm{v}}=\frac{\rho_{\mathrm{ct}}-\rho_{\mathrm{ce}}}{\rho_{\mathrm{ca}}}
$$

Micro-hardness. Hardness is the resistance of a material to deformation, indentation or scratching. The basic goal of hardness testing is to quantify the resistance of a material to plastic deformation. The indentation value has high importance for technical applications which reflects the resistance to deformation which is a complex property and related to modulus, strength, elasticity, plasticity and dimensional stability of a material. Hardness is generally classified into three different categories with respect to the depth of indentation (d). When the depth of indentation ranges between $1-50 \mu \mathrm{m}$, it is termed as micro hardness. The test methods commonly used for expressing the relationship between hardness and the size of impression are Brinell, Vicker's and Rockwell hardness tests.

Measurement of hardness. Hardness values offer a comparative measurement of a material's resistance to plastic deformation from a standard source, as different hardness techniques have different scales. The Vickers hardness test is very popular among researchers since it is easier to perform compared to other hardness tests and also the hardness calculations are independent of the size of the indenter and load applied. In this study, Vicker's hardness test setup is used to find out the microhardness values of different composites. Microhardness testing is carried out in a UHL micro hardness tester (Model - VMHT MOT, Sl. No. 1002001, Technische Mikroskopie) with a Vickers diamond indenter. The specimen used for the test is of the dimension of $16 \mathrm{~mm} \times 12 \mathrm{~mm} \times$ $6 \mathrm{~mm}$. Fig. 3 shows the Vicker's microhardness test setup. The dwell time is kept at 10s while the speed of indentation is set at $50 \mu \mathrm{m} / \mathrm{s}$ and indentation load of $1000 \mathrm{kgf}$. The two diagonals $\left(\mathrm{d}_{1}\right.$ and $\mathrm{d}_{2}$ ) of the indentation left in the surface of the material after removal of the load are measured using a microscope and their average (d) calculated. Vickers hardness (HV) is calculated with the following equation:

$$
\mathrm{HV}=\frac{1.8544 \mathrm{~F}}{\mathrm{~d}^{2}}
$$

where load $(\mathrm{F})$ is in Kilogram force and the mean of two diagonals created by the pyramidal indent (d) is in millimeter. It should be mentioned here that as the hardness is measured on the finished test sample surfaces where glass fiber orientation is perpendicular and no separate surface preparation is done, an average of at least three hardness values for each sample is reported.

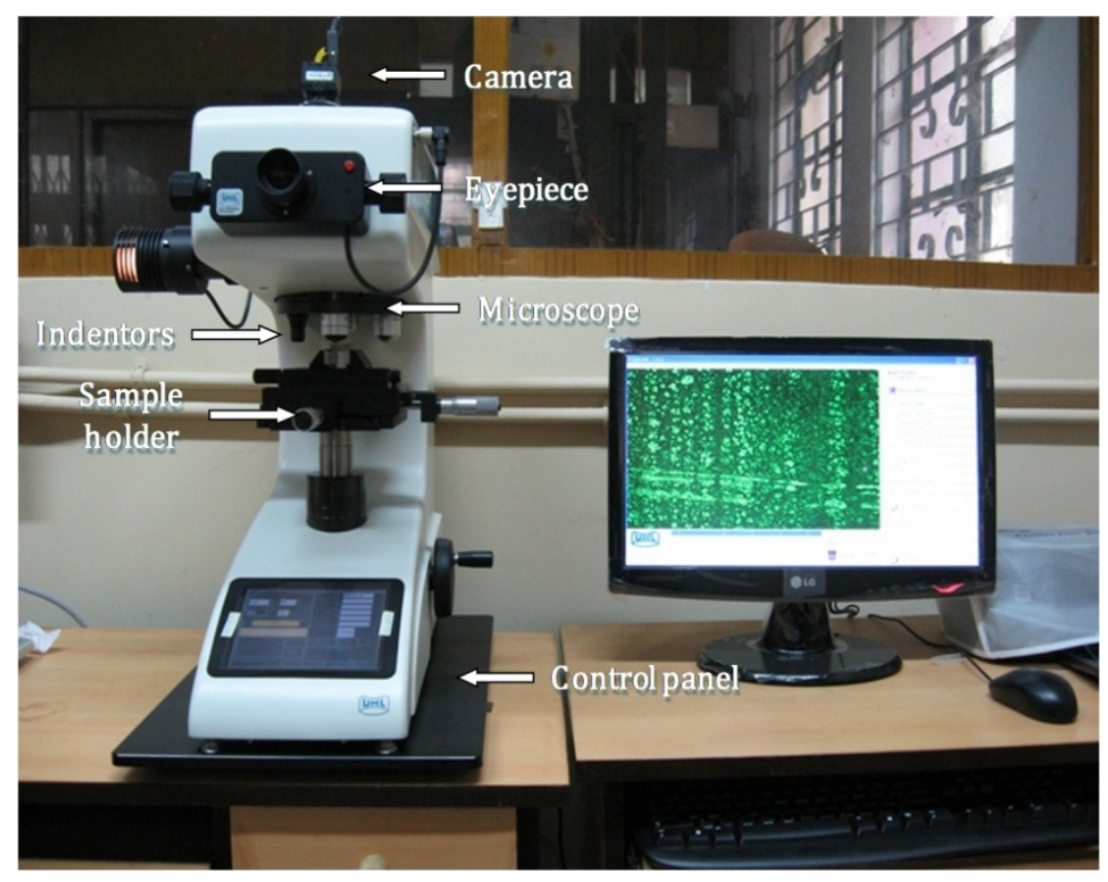

Figure 3. Vicker's microhardness tester. 
Tensile strength. The tensile tests are conducted on INSTRON 8801 as per ASTM D3039-07 standards test method for tensile properties of composite specimens. This test method determines the in plane tensile properties of glass epoxy composites with or without aluminium particulate filler. The dimension of the sample is $150 \mathrm{~mm} \times 12 \mathrm{~mm} \times 6 \mathrm{~mm}$ with a fixed gauge length of $100 \mathrm{~mm}$. Tests are conducted for the samples at normal room temperature (27Deg C) and quasistatic strain-rate of $10 \mathrm{E}-4 / \mathrm{s}$. At least three specimens for each composite are tested to get the mean value of the tensile strength. INSTRON 8801 with tensile test setup and the test specimens are shown in Fig. 4.
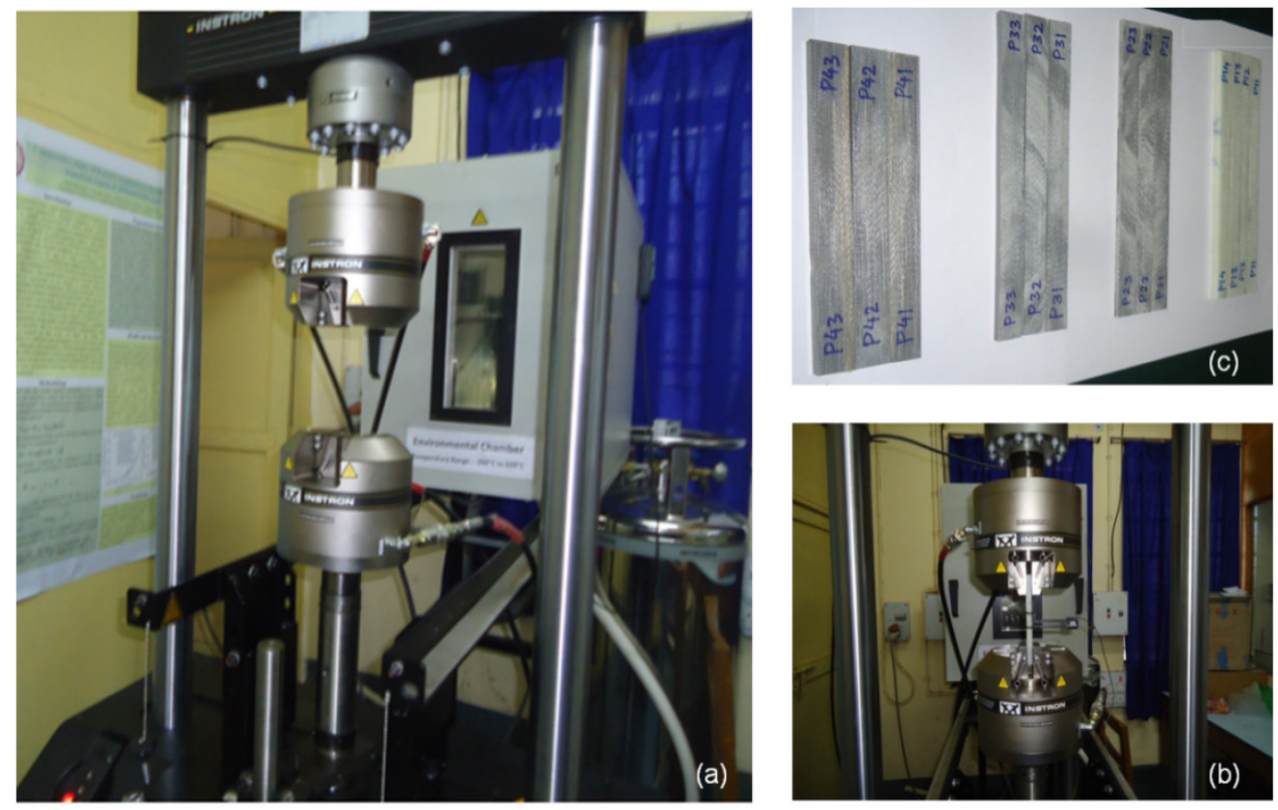

Figure 4. a) INSTRON 8801, b) tensile test setup, c) test samples.

Flexural and inter laminar shear strength (ILSS). The flexural strength of a composite is the maximum tensile stress that it can withstand during bending before reaching the breaking point. The three point bend test is conducted on glass epoxy and aluminium powder filled glass epoxy composite samples using a testing machine INSTRON 8801 as per ASTM D790-10 standard test method. The dimension of each specimen is $60 \mathrm{~mm} \times 12 \mathrm{~mm} \times 6 \mathrm{~mm}$ with a span of $50 \mathrm{~mm}$ length and a constant cross head-speed of $1.5 \mathrm{~mm} / \mathrm{min}$ is maintained. The arrangement for the test and the test specimen are shown in Fig. 5. For both flexural strength and ILSS, the test is repeated three times for each composite type and the mean value is reported. The flexural strength of the composite specimen is determined using the following equation:

$$
\text { Flexural strength }=\frac{3 \mathrm{PL}}{2 \mathrm{bt}^{2}},
$$

where $\mathrm{L}$ is the span length of the sample $(\mathrm{mm})$; $\mathrm{P}$ is maximum load $(\mathrm{N})$; b the width of specimen $(\mathrm{mm}) ; \mathrm{t}$ the thickness of specimen $(\mathrm{mm})$; The data recorded during the three point bend test is used to evaluate the Inter laminar shear strength (ILSS). The ILSS values are calculated as follows:

$$
\mathrm{ILSS}=\frac{3 \mathrm{P}}{4 \mathrm{bt}} \text {. }
$$



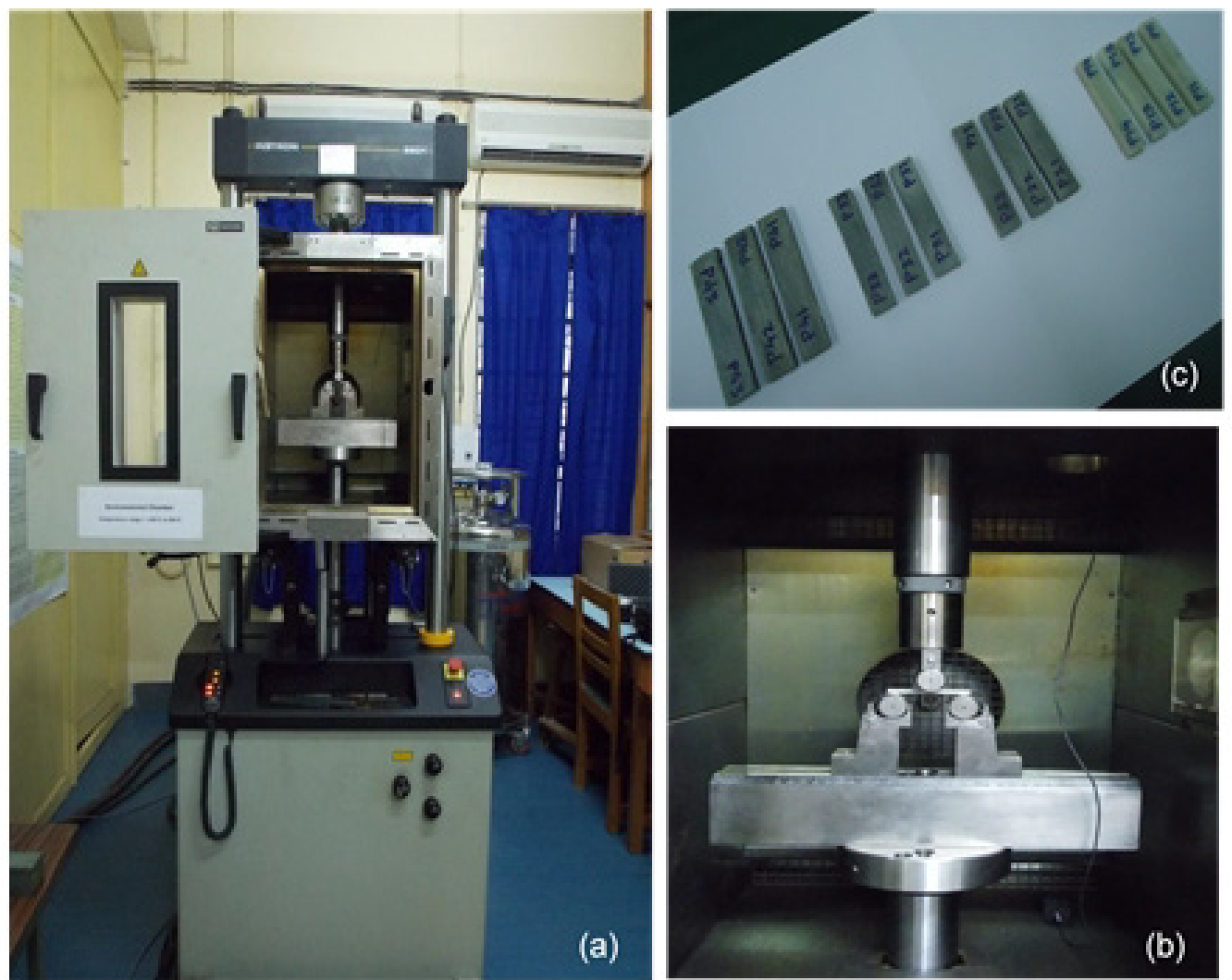

Figure 5. a) INSTRON 8801 with 3-point bending fixture; b) larger image of the fixture showing the point of loading; c) test samples.

\section{Result and Discussions}

The mechanical properties of glass epoxy and aluminium powder filled glass epoxy composites with different filler concentration are studied. The relative effects of aluminium filler concentration on various mechanical properties of the composites are presented with respect to filler concentration.

Density and void fraction. Density is a material characteristic which is of prime importance in several weight sensitive applications. Density of a composite depends on the relative proportion of matrix and the reinforcing materials. There is always a difference between the measured and the theoretical density values of a composite due to the presence of voids and pores. These voids significantly affect some of the mechanical properties and even the performance of composites. Higher void contents usually mean lower fatigue resistance, greater susceptibility to water penetration and weathering [25]. The knowledge of void content is desirable for estimation of the quality of the composites. The theoretical and measured density of glass epoxy and aluminium particulate glass epoxy composites, along with the corresponding volume fraction of voids is presented in Table 5. It is found that the composite density values calculated theoretically from weight fractions using equation ( 1 and 2 ) are not equal to the experimentally measured values, as expected. It is evident from Table 5 that density and void fraction of glass epoxy composite increase with the incorporation of aluminium powder. 
Table 5. Measured and theoretical densities along with the void fractions of glass epoxy and glass epoxy filled with aluminium powder composites.

\begin{tabular}{|c|c|c|c|c|c|}
\hline \multicolumn{2}{|c|}{ Composition } & $\begin{array}{c}\text { Measured } \\
\text { density } \\
\text { (gm/cc) }\end{array}$ & $\begin{array}{c}\text { Theoretical } \\
\text { Density } \\
\text { (gm/cc) }\end{array}$ & $\begin{array}{c}\text { Volume } \\
\text { fraction } \\
\text { of voids (\%) }\end{array}$ \\
\hline $\mathrm{C}_{2}$ & $60 \mathrm{GE}$ & Epoxy $(40 \mathrm{wt} \%)+$ Glass Fiber \\
$(60 \mathrm{wt} \%)$ & 1.77 & 1.79 & 1.11 \\
\hline $\mathrm{D}_{1}$ & $5 \mathrm{AlGE}$ & $\begin{array}{c}\text { Epoxy }(35 \mathrm{wt} \%)+\text { Glass Fiber } \\
(60 \mathrm{wt} \%)+5 \mathrm{wt} \% \text { Aluminium }\end{array}$ & 1.84 & 1.87 & 1.60 \\
\hline $\mathrm{D}_{2}$ & $10 \mathrm{AlGE}$ & $\begin{array}{c}\text { Epoxy }(30 \mathrm{wt} \%)+\text { Glass Fiber } \\
(60 \mathrm{wt} \%)+10 \mathrm{wt} \% \text { Aluminium }\end{array}$ & 1.91 & 1.95 & 2.05 \\
\hline $\mathrm{D}_{3}$ & $15 \mathrm{AlGE}$ & $\begin{array}{c}\text { Epoxy }(25 \mathrm{wt} \%)+\text { Glass Fiber } \\
(60 \mathrm{wt} \%)+15 \mathrm{wt} \% \text { Aluminium }\end{array}$ & 1.97 & 2.03 & 2.95 \\
\hline
\end{tabular}

Micro-hardness. Hardness is considered as one of the most important factors that govern the wear resistance of any material. In the present work, micro-hardness values of glass epoxy and glass epoxy composites with different aluminium concentrations are obtained. The test results (Fig. 6) show that with the presence of aluminium filler upto $10 \mathrm{wt} \%$, microhardness of the composites is improved as compared to unfilled glass epoxy and with further addition of aluminium up to $15 \mathrm{wt} \%$, micro hardness decreases.

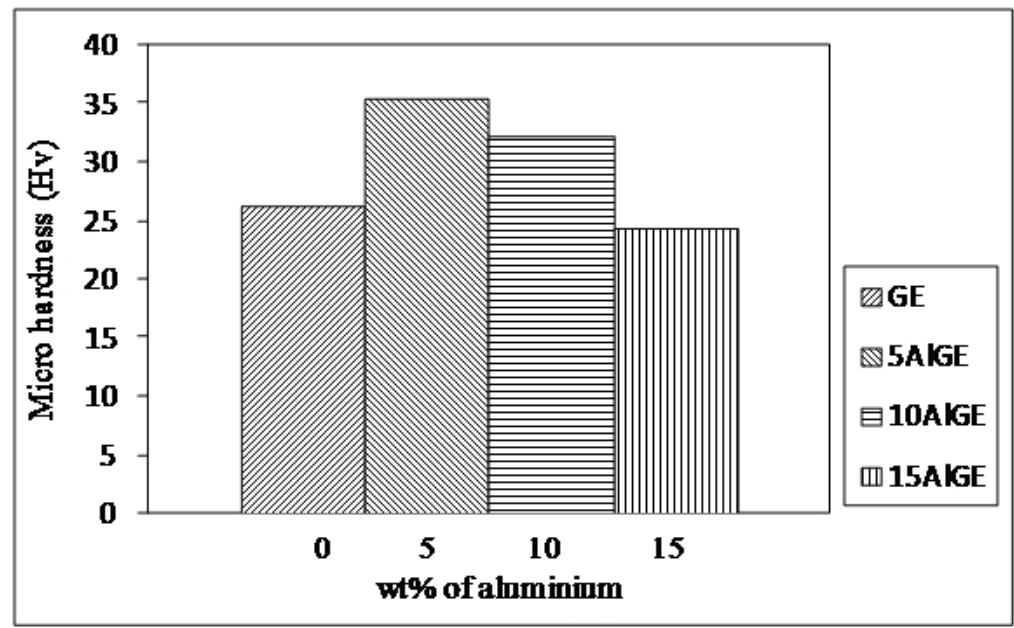

Figure 6. Micro-hardness of composites with aluminium concentration.

Tensile Properties. The tensile strengths of glass epoxy and glass epoxy composites filled with aluminium powder are shown in Fig. 7. It is found that, there is a gradual drop in tensile strength with increase in aluminium content. The unfilled glass epoxy composite has strength of 347.60 $\mathrm{MPa}$ in tension, and this value drops to $306.64 \mathrm{MPa}, 278.75 \mathrm{MPa}$ and 210.29 $\mathrm{MPa}$ with aluminium powder addition of $5 \mathrm{wt} \%, 10 \mathrm{wt} \%$ and $15 \mathrm{wt} \%$ respectively. The reduction in tensile strength with filler addition may be due to the chemical bond strength between filler particles and the matrix is too weak to transfer the tensile load or the sharp corners of irregular shaped filler particles result in stress concentration zones in the matrix body during tensile loading or due to the increase in void percentage in the composites with increase in filler content [26]. 


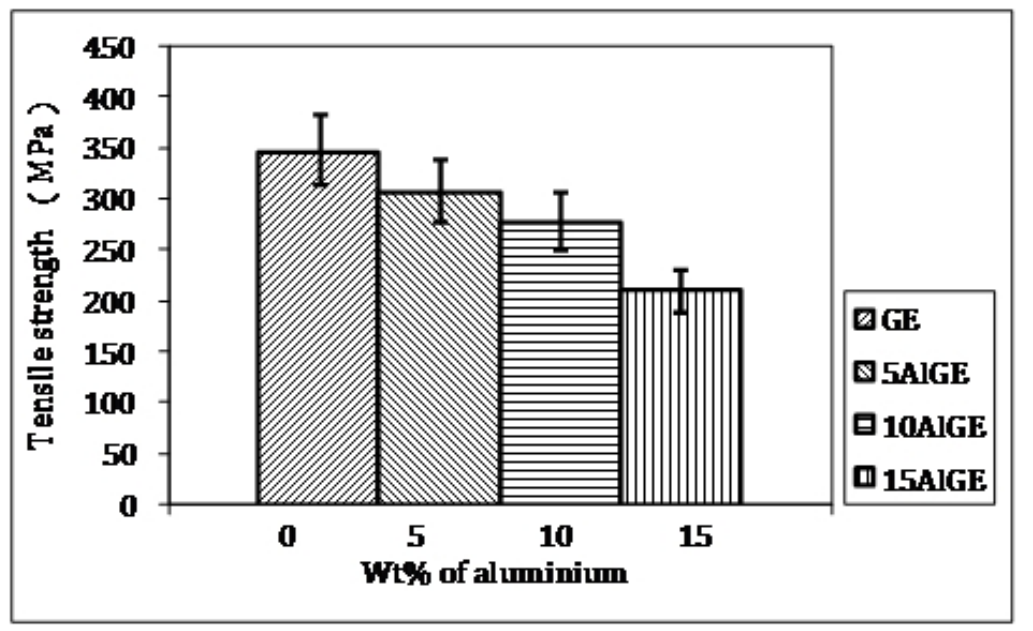

Figure 7. Tensile strength of composites with different aluminium concentration.

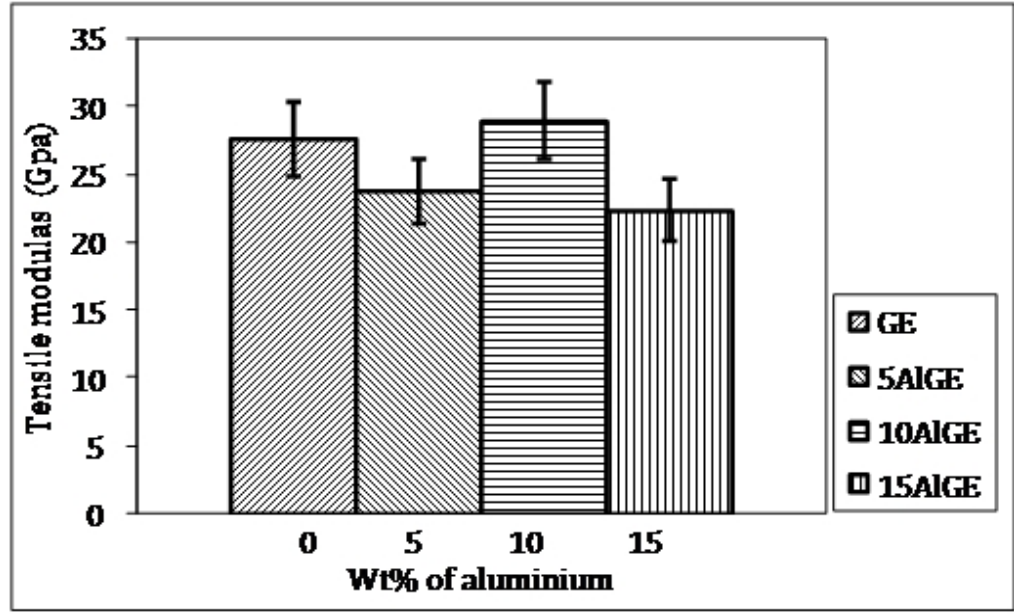

Figure 8. Tensile modulus of composites with different aluminium concentration.

The variation of tensile modulus with different aluminium concentration in glass-epoxy composites is shown in Fig. 8. It is observed that the tensile moduli of glass epoxy composites improve significantly with $10 \mathrm{wt} \%$ of aluminium powder content (10AlGE). But in case of 5 and $15 \mathrm{wt} \%$ aluminium powder filled glass epoxy composites (5AlGE and 10AlGE), it decreases with respect to unfilled glass epoxy composite (GE). Previous reports demonstrate that normally the fibers in the composite restrain the deformation of the matrix polymer, reducing the tensile strain $[27,28]$. So even if the strength decreases with filler addition, the tensile modulus of the composite is expected to increase for a certain $\mathrm{wt} \%$ of aluminium powder addition as observed in the present investigation. But further increase in filler content up to $15 \mathrm{wt} \%$ or to decrease it to $5 \mathrm{wt} \%$, the tensile moduli of the composites are found to be decreasing.

Flexural Strength. Composite materials used in structures are prone to fail in bending and therefore the development of new composites with improved flexural characteristics is essential. The variation of flexural strength of glass-epoxy composites with different $\mathrm{wt} \%$ of aluminium filler concentration is shown in Fig. 9. The highest improvement in flexural strength with $5 \mathrm{wt} \%$ of aluminium content is recorded whereas $15 \mathrm{wt} \%$ aluminium filled glass epoxy composite shows the lowest strength even lower than the unfilled composite. But for the composite with $10 \mathrm{wt} \%$ of aluminium powder shows the better performance than glass epoxy composite but less than the $5 \mathrm{wt} \%$ aluminium filled composite. The improvement in the flexural strength of the composites with filler content (upto $10 \mathrm{wt} \%$ ) is probably caused by good compatibility of the particulates and the epoxy matrix, leading to increase in interfacial bonding. The lower values of flexural properties (as 15AlGE) may also be attributed to fiber to fiber interaction, voids and dispersion problems. 
Inter laminar shear strength (ILSS). The variation of inter-laminar shear strength (ILSS) of glass epoxy and glass epoxy with aluminium filler composites is presented in Fig. 10. It is observed that with the addition aluminium powder up to $10 \mathrm{wt} \%$, the ILSS of glass epoxy composites increases in comparison to unfilled glass epoxy composite but starts decreasing on further aluminium addition. This reduction may be due to the formation of voids in the matrix which is generally located at the inter-laminar region of composites or may be because of poor interfacial bond among the constituents of the composites. The maximum value of ILSS is observed for glass epoxy with $5 \mathrm{wt} \%$ aluminium concentration. The present study reveals that incorporation of aluminium in glass fiber epoxy composites should be done judiciously particularly with respect to its amount; otherwise there may be deterioration of mechanical properties. Also there are other aspects of composite preparation [29-32] that needs to be care of for enhancement of properties.

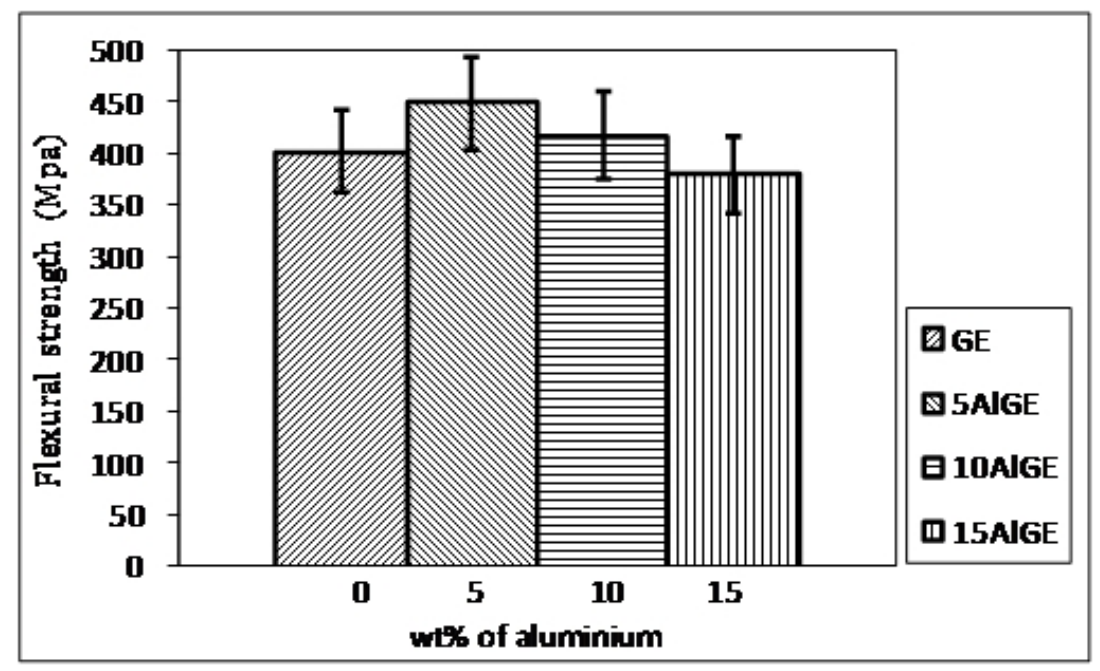

Figure 9. Flexural strength of composites with different aluminium concentration.

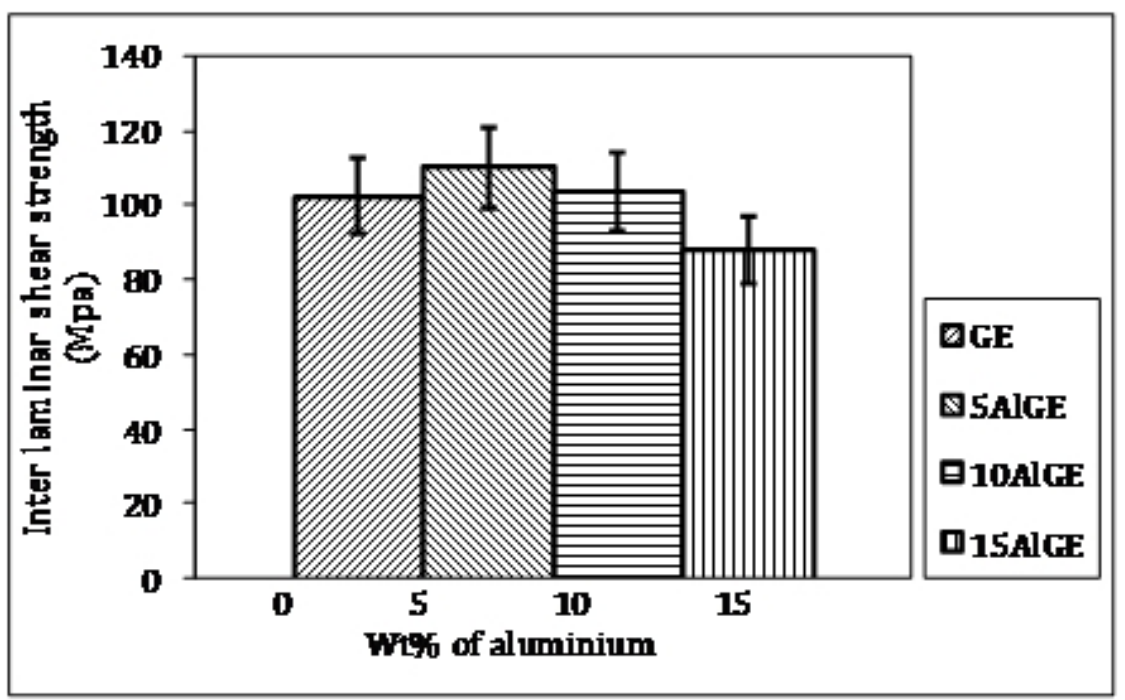

Figure 10. Inter-laminar shear strength of composites with different aluminium concentration.

\section{Conclusions}

In this study, processing and experimental investigations are conducted to evaluate the mechanical properties of woven glass-fiber reinforced epoxy composites filled with different proportion of aluminium powder. The following main conclusions are drawn from the study:

1. Fabrication of woven glass fiber reinforced epoxy composites filled with different proportion (wt $\%$ ) of aluminium powder is possible in simple hand lay-up technique followed by light compression molding process. 
2. The density and void fractions of glass epoxy composites increase with increase in aluminium concentration.

3. Micro hardness, flexural strength, inter laminar shear strength (ILSS) of 5 and $10 \mathrm{wt} \%$ aluminium content composites are improved than unfilled glass epoxy composite and these properties decrease with further addition of aluminium powder. With respect to these mechanical properties, $5 \mathrm{wt} \%$ aluminium content yields the maximum property values whereas $15 \mathrm{wt} \%$ aluminium yields the minimum value.

4. The tensile strength of the glass fiber reinforced epoxy composites decreases effectively with increasing aluminium proportion.

5. In order to reach the best tensile modulus properties, the optimal content of aluminium powder in the filled epoxy matrix is recommended as $10 \mathrm{wt} \%$.

\section{Acknowledgements}

Authors gratefully acknowledge the support of University Grants Commission (UGC), Govt. of India through Major Research Project [F. No. 42-882/2013(SR)] in Engineering.

\section{References}

[1] D. Hull, T.W. Clyne, An introduction to composite materials, Cambridge university press, 1996.

[2] F.T. Wallenberger, J.C. Watson, H. Li, Glass fibers, Materials Park, OH, ASM International, 2001.

[3] R.M. Wang, S.R. Zheng, Y.G. Zheng, Polymer matrix composites and technology, Elsevier, 2011.

[4] N. Mohan, C.R. Mahesha, R. Raja, Tribo-mechanical behaviour of SiC filled glass-epoxy composites at elevated temperatures, International Journal of Engineering, Science and Technology. 6 (2014) 44-56.

[5] B. Shivamurthy, M.S. Prabhuswamy, Influence of $\mathrm{SiO} 2$ fillers on sliding wear resistance and mechanical properties of compression moulded glass epoxy composites, Journal of Minerals and Materials Characterization and Engineering. 8 (2009) 513-530.

[6] A. Nadia et al., Effect of $\mathrm{Al}_{2} \mathrm{O}_{3}$ and $\mathrm{SiO}_{2}$ nanoparticle on wear, hardness and impact behavior of epoxy composites, Chemistry and Materials Research. 7 (2015) 34-39.

[7] D. Lingaraju et al., Mechanical and tribological studies of polymer hybrid nanocomposites with nano reinforcements, Bull. Mater. Sci. 34(4) (2001) 705-712.

[8] B.R. Raju et al., Investigations on mechanical and tribological behaviour of particulate filled glass fabric reinforced epoxy composites, Journal of Minerals and Materials Characterization and Engineering. 4 (2013) 160-167.

[9] O. Asi, An experimental study on the bearing strength behavior of $\mathrm{Al} 2 \mathrm{O} 3$ particle filled glass fiber reinforced epoxy composites pinned joints, Compos. Struct. 92(2) (2010) 354-363.

[10] K. Devendra, T. Rangaswamy, Determination of mechanical properties of $\mathrm{Al} 2 \mathrm{O} 3, \mathrm{Mg}(\mathrm{OH}) 2$ and $\mathrm{SiC}$ filled E-glass/epoxy composites, International Journal of Engineering Research and Applications. 2 (2012) 2028-2033.

[11] S. Erden et al., Enhancement of the mechanical properties of glass/polyester composites via matrix modification glass/polyester composite siloxane matrix modification, Fibers and Polymers. 11 (2010) 732-737. 
[12] B. Suresha, G. Chandramohan, N.M. Renukappa, Mechanical and tribological properties of glass-epoxy composites with and without graphite particulate filler, J. Appl. Polym. Sci. 103(4) (2007) 2472-2480.

[13] M.K. Paliwal, S.K. Chaturvedi, An experimental investigation of tensile strength of glass composite materials with calcium carbonate $(\mathrm{CaCO} 3)$ filler, International Journal of Emerging Trends in Engineering and Development. 2 (2012) 303-309.

[14] L. Yusriah, M. Mariatti, A. Abu Bakar, Mechanical properties of particulate filler/woven glass fabric filled vinyl ester composites, Journal of Vinyl and Additive Technology. 16(1) (2010) 98-104.

[15] V.K. Srivastava, J.P. Pathak, K. Tahzibi, Wear and friction characteristics of mica-filled fiberreinforced epoxy resin composites, Wear. 152(2) (1992) 343-350.

[16] V.K. Srivastava, S. Wahne, Wear and friction behaviour of soft particles filled random direction short GFRP composites, Mater. Sci. Eng. A. 458(1) (2007) 25-33.

[17] P.R. Pati, A. Satapathy, Processing and characterization of glass-epoxy composites filled with Linz-donawitz (LD) slag, Universal Journal of Mechanical Engineering. 3 (2015) 7-11.

[18] S.K. Bhattacharya, Metal filled polymers, Vol. 11, CRC Press, 1986.

[19] S. Chung et al., Evaluation for micro scale structures fabricated using epoxy-aluminum particle composite and its application, J. Mater. Process. Technol. 160(2) (2005) 168-173.

[20] W. Zhou, D. Yu, Effect of coupling agents on the dielectric properties of aluminum particles reinforced epoxy resin composites, J. Compos. Mater. 45(19) (2011) 1981-1989.

[21] W. Zhou, Effect of coupling agents on the thermal conductivity of aluminum particle/epoxy resin composites, J. Mater. Sci. 46(11) (2011) 3883-3889.

[22] N. Senthilkumar, K. Kalaichelvan, K. Elangovan, Mechanical behavior of aluminium particulate epoxy composite - Experimental study and numerical simulation, International Journal of Mechanical and Materials Engineering. 7 (2012) 214-221.

[23] P.V. Vasconcelos et al., Impact fracture study of epoxy-based composites with aluminium particles and milled fibers, J. Mater. Process. Technol. 170(1) (2005) 277-283.

[24] G.M. Hamed, Study the tensile strength for epoxy composite reinforced with fibers particles, Journal of University of Anbar for Pure Science. 3 (2009).

[25] B.D. Agarwal, L.J. Broutman, K. Chandrashekhara, Analysis and performance of fiber composites, John Wiley \& Sons, 2006.

[26] A.K Rout, A. Satapathy, Study on mechanical and tribo-performance of rice-husk filled glass-epoxy hybrid composites, Materials \& Design. 41 (2012) 131-141.

[27] S.Y. Fu, B. Lauke, Characterization of tensile behaviour of hybrid short glass fibre/calcite particle/ABS composites, Composites Part A: Applied Science and Manufacturing. 29(5) (1998) 575-583.

[28] J.L. Thomason et al., Influence of fibre length and concentration on the properties of glass fibre reinforced polypropylene: Part 3. Strength and strain at failure, Composites Part A: Applied Science and Manufacturing. 27(11) (1996) 1075-1084.

[29] J. Gu et al., Highly thermally conductive flame-retardant epoxy nanocomposites with reduced ignitability and excellent electrical conductivities, Composites Science and Technology. 139 (2017) 83-89. 
[30] J. Gu et al., Synthesis of cyanate ester microcapsules via solvent evaporation technique and its application in epoxy resins as a healing agent, Industrial \& Engineering Chemistry Research. 55(41) (2016) 10941-10946.

[31] H. Gu et al., An overview of multifunctional epoxy nanocomposites, Journal of Materials Chemistry C. 4(25) (2016) 5890-5906.

[32] J. Gu et al., Development of wave-transparent, light-weight composites combined with superior dielectric performance and desirable thermal stabilities, Composites Science and Technology. 144 (2017) 185-192. 